\title{
Exploring the Effects of Work Life Balance on Employee Performance in the Banking Sector: A Case study of AB Bank in Lusaka-Zambia.
}

\author{
${ }^{1}$ Jacqueline Siwale; ${ }^{2}$ Dr. Chrine Hapompwe; ${ }^{3}$ Dr. Crispin Kukano; $\&{ }^{4}$ Febby Latoya Mwiikisa \\ ${ }^{1}$ Lecturer- Lecturer \& Programme Co-ordinator-Texila American University \\ ${ }^{2}$ Lecturer - Arts, Education \& Social Sciences Faculty - Cavendish University Zambia \\ ${ }^{3}$ Lecturer - Arts, Education \& Social Sciences Faculty - Cavendish University Zambia \\ ${ }^{4}$ Graduate- Business and Information Technology Faculty-Cavendish University-Zambia \\ DOI: 10.29322/IJSRP.11.06.2021.p11416 \\ http://dx.doi.org/10.29322/IJSRP.11.06.2021.p11416
}

\begin{abstract}
The purpose of the study was to explore management of work life balance and employee performance in the banking sector with special reference to AB Bank branches in Lusaka-Zambia. The study used a mixed method design employing both qualitative and quantitative methods. With a target population of 500 and the sample size of 222 members of staff using Israel Yamane's sampling formula. Purposive sampling was used to select the 22 managers to be interviewed, and the stratified and random sampling techniques were used to select equal numbers of people from the various branches and departments to make up the 200 members of staff as a unit of analysis. Data were analyzed using computer based statistical data analysis package, SPSS (version 16.0) for quantitative data and content analysis for qualitative data. The data analysis included univariate and bivariate analyses. Using the Pearson's Product Moment Correlation with one - tailed test of significance, the correlation analysis was made to investigate the phenomena. The study observed poor organizational work culture in AB Bank branches bordering on issues of work life balance which included various factors such as work environment, human resource policies, job insecurities, compensation packages, among others. Moreover, from simple regression analysis, work life balance was found to have a positive impact on employee performance. Findings of this study revealed that parenting and pregnancy policy has no impact on the employee's performance. Pregnant and parent employees mainly expect maternity leave for adoption and it is covered from the leave arrangements. This also indicates that AB Bank should prioritize creating different work life balance practices for employees by enhancing the use of work life-balance options like flexi time; job sharing and breaks from work so that employees can feel that the organization is facilitating their coordination of family and professional lives.
\end{abstract}

Index words: Exploring, Management, Work Life Balance, Employee Performance, AB Bank.

\subsection{INTRODUCTION}

In the current working world, the systems being used in the management of human capital are changing. However, with the change in work culture, where work is becoming more humane, human capital is now considered in different ways. Instead of just looking at what the employee can produce at the workplace, current business practice is that the employees must be seen as complete and holistic human beings with a life beyond work. Also, in the last few years, employees have been struggling with a growing number of competing demands between their work and private lives. These demands are caused by globalization, technological advances, workplace changes, and demographic changes. This has called for the inclusion of work life balance as a key component of business and human resource management. Although work-life balance has received much attention from scholars and practitioners, there are still some gaps in the existing literature since the consequences of work-life balance and the related work-life balance policies and practices have not been fully identified. Thus the study will look at the effects of work life balance on employee performance in the banking sector, looking specifically at the case of AB Bank Zambia.

The banking sector is one of the most human resource intensive sector. Banking employees stay in the bank for longer hours doing routine work, which could be highly tasking on their mental health. With the current state of the working world, the role of human resource in organizational development has begun to be taken more seriously. It has been realized that human resource are beyond just productive tools at work, but their effectiveness stretches to how well the other areas of their lives are. With work life balance, an organisations can ensure that their human resource are well taken care of beyond just work but in other areas as well. It takes a holistic approach to life. This realization is based on the understanding that the value of human resource without people, the organisations may not achieve its objectives. Currently, work-life balance has become a progressively persistent concern to both 
employers and employees of most organisations. In recent time, there has been an increase in the contemplation of the pressures that work has on family as well as life of employees. This has prompted research focusing on work-life. Work is generally considered as a part of life. Though separated by certain physical, psychological and temporal boundaries, the two concepts are operationalized within the same context of time and space. This study specifically zooms in on effects of work life balance on employee performance in the banking sector. It takes a study of AB Bank Zambia. AB Bank Zambia Limited is a new commercial micro-finance bank in the Access Micro-finance Holding Network whose main customers and clients are the micro, small and medium-sized entrepreneurs (SME's) as well as the low income earners in Zambia. AB Bank Zambia aims to evolve into one of the leading providers of financial services to this target group in Zambia and to set industry standards in terms of the speed, ease and quality of MSME banking. The bank's mission is "to improve access to a broad range of financial services for the majority of Zambians and their businesses through the build-up of a solid branch network and the implementation of technology based product solutions for the target group".

AB Bank was founded by Access Holdings in collaboration with four of its longstanding partners: KFW Development Bank, the International Finance Corporation, the Dutch development finance institution FMO, and the Belgium-based Impulse Microfinance Fund. As at now, the bank only has branches in Lusaka, but it aims at growing to other parts of the country. In terms of service, the bank offers a range of loan and deposit products focusing on the core clientele of micro, small and medium-sized enterprises as well as the general lower-/middle income groups of the country. Banking services include term deposit, saving and current accounts as well as a saving plan and payment services such as a salary project, mobile payment and money transfer systems.

The banking sector is known as one of the most stressful industry, particularly due to the nature of work and work hours. Also, the Zambian banking sector has undergone a wide range of reforms in recent years leading to increased demands from customers and regulators with regard to the availability and quality of worker service delivery. These reforms were brought about by the fluctuating state of the economy, unstable monetary policy, new competitive repositioning, innovation in communication and information processing resulting in a rapid change in Zambia's business environment. These changes have also affected banking work and may have increased the challenges of balancing work and family roles among bank workers. This trend may have a negative influence on the individuals because, generally, the Zambian culture places some values on the family system. Consequently, the failure of a family system is termed as a failure on the individual's part which tends to affect success of the individual (Maxwell \& McDougall, 2004). Managing multiple roles, such as engagement in work, in employee and spouse interaction and involvement in domestic roles could affect the effectiveness of employees as explained by (Hofacker \& Konig, 2013).

In other words, when employees invest resources in jobs that are beyond their call of duty, perceive their workload to be more than they can handle or appraise the demand of their work as exceeding their resources, they are likely to experience interference from their work with their family lives due to little time left to allocate to their family roles (Hall \& Richter, 1998). The mechanisms by which the provision of work-life practices affects both employee behaviour and employee productivity remains unclear and underresearched (Maxwell \& McDougall, 2004). This study is therefore aimed at exploring the effect of work-life practices in the banking industry, with a focus on AB Bank Zambia. It attempts to gain a better understanding of the experiences and expectations of employees in an attempt to identify the source of the work-life balance and its effect on Employee performance as well suggest ways in which organisations can assist employees to achieve better work-life balance and improve their performance and wellbeing.

\subsection{Statement of the problem}

The Zambian banking sector is known for its long hour work culture, and high work load of employees. This lack of work flexibility, high work pressure and longer working hours are stressing out many workers in the Zambian Banks, reducing their job performance and productivity as well as causing broken homes (Bodibe, 2006). Also, personal issues that employees of selected commercial banks face outside work may demoralize them and in turn their service delivery to customers. As a result of spending too many hours at work with very little time for personal activities and family, most bankers end up not living a full and holistic life. This in turn may affect their performance, with a chain reaction affecting customers. All these may result in customers threatening to withdraw their patronage from the banks. Moreover, due to the nature of the work environment, commercial banks now go into strategic alliances with other banks, by merger and acquisition which entail expansion, increasing capital base and customer base. These have led to managers having higher expectation of employees' performance and therefore a misplacement of priority of interest by the employees trying to meet up with the target of the banks, which may affect their personal life. Hence, the study of work-life balance and employee performance is imperative (Spathis, Petridou, and Glaveli, 2007) .The multi-faced demand between work and home responsibilities have assumed increased relevance for employees in commercial banks in recent years. This is due to demographic and workplace changes such as; transformation in family structures, growing reluctance for long number of hours, acceptance culture, greater number of women in the workforce and technological advancement. All these have resulted in the employees having difficulty in prioritizing between their work roles and their personal lives, which ultimately affect the banks. Thus emphasizing the essence of this study.

\subsection{Study Objectives}

- To explore the effects of work life balance on employees' performance.

- To describe obstacles to and areas for improving work-life balance among employees at AB Bank. 


\subsection{THEORETICAL REVIEW OF LITERATURE}

A theoretical framework includes concepts and, accompanied by their definitions and reference to pertinent scholarly literature, existing theories used for a particular study. This demonstrates an understanding of theories and concepts that are relevant to the topic of a research paper and that relate to the broader areas of knowledge being considered (Labaree, 2009). The theoretical framework used in this study is the Spillover Effect by Aaron Makafui Ametorwo (2016). The spillover effect model is used in this study to explain the work life balance on employee performance. According to this theory, work family-spillover involves the transfer of thoughts and behaviour between the work and family domains. As a result, experiences from one domain are likely to affect experiences in the other. Spillover is usually limited to the inter-domain and within the individual or intra-individual. This study aims to show how spillover is not limited to the individual experiencing the strain and stress, but is also extended to their workplace, clients and customers and significant others. It is noted that this is a process that results from psychological strain of individual experiences that have the capacity of affecting the levels of strain in another individual in the same social environment. This means that in spillover, individuals in the same work setting or home environment as the individual experiencing the strain and stress can also be affected by such emotions thereby generating similar reactions in them. Therefore, spillover can be simply described as intra-individual, inter-domain contagion of stress.

Figure 1: The Spillover Model.

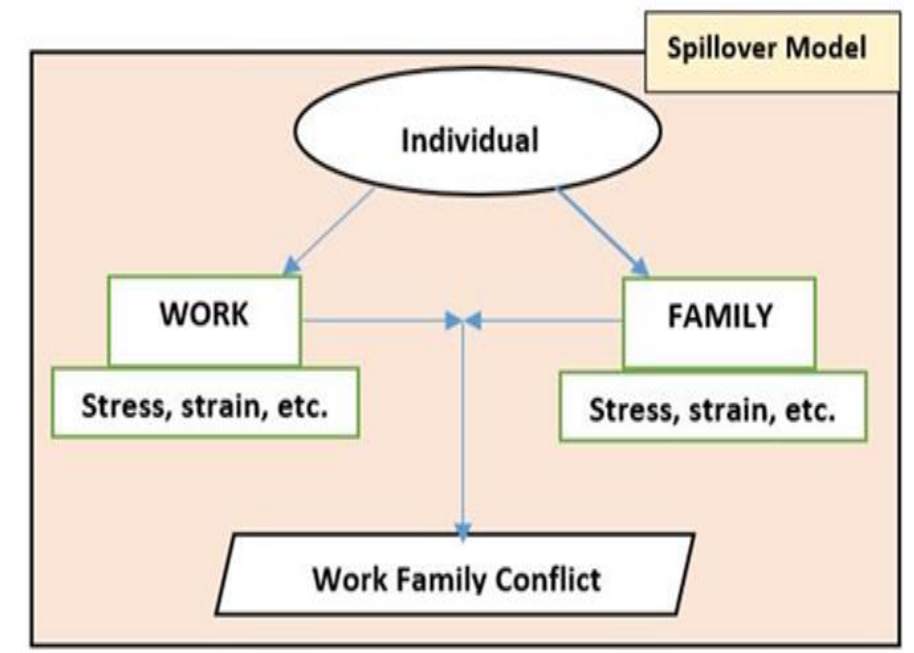

Adopted from Aaron Makafui Ametorwo (2016) in Managing Work Family Conflict among Female Entrepreneurs in Ghana for Development, International Journal of Economics, Business and Management Studies, 3(1): 21-35

\subsection{Application of the Theoretical Framework to the Study}

Work-Life balance has become a primary concern to employers and policy makers in the banking sector because of the time that bank employees spend in the bank. Their work pressures are likely to spill over to their home life. On the other hand, the effects of not spending much time at home, or with non-work related programs, their home pressures might also spill over and affect work productivity. It is important, therefore, that programs be deliberately implemented to create a balance between the two domains. There is need for a situation where what is gained in the work domain might become a positive spillover to the home domain, and vice versa. For instance, work opportunities and resources can be utilised to encourage growth and better functioning in the home domain. This spillover theory has been proved useful in explaining how positive or negative experiences can be transferred from one life role to the other.

\subsection{The Concept of Work Life Balance}

A number of scholars have defined Work Life Balance differently. One of the most common definitions of work life balance is by Tomlinson (2016) who says that it is the division of one's time and focus between working and family or leisure activities. However, this definition is a bit too simplistic and can be enhanced. It is at this point that Lowe (2005) proposes that work life balance is a term commonly used to describe the balance that a working individual needs between time allocated for work and other aspects of life. In essence, as posited by Hall \& Richter (1998), the practice of work life balance are not a one size fits all affair. They depend on the organization and the form of organizational culture in that organization. The definitions may differ but the underlying goal is the transition from looking at work-life balance practices exclusively as a means of accommodating individual personnel with care giving tasks to identifying their input to organizational performance (Kalliath and Brough, 2008). In the same line, 
ISSN 2250-3153

Tomlinson (2016) contends that work life balance is generally about employees' feeling that their work does not interfere with their home affairs and so that they can operate as great employees, but also as great family members.

\subsection{Elements of Work Life Balance}

The best way to understand work life balance is by understanding the elements that make up work like balance. As proposed by Beauregard, (2006) work life balance involves among other things, track your time, determining your priorities, set specific personal and organizational objectives and scheduling them productively. It also involves establishing boundaries between work and home life, taking care of employee health and nurturing family/relationships. By extension, Kumar, (2013) suggests that this includes, flexi time, supporting children's education, employees' participation in volunteer work, or facilitate phased retirement. Flexi time allows employees, to determine, or be involved in determining, the start and end times of their working day, provided a certain number of hours is worked. This can allow them to meet family or personal commitments/emergencies, enable employees to respond to both predictable and unpredictable circumstances, during the day or to reduce their commuting time by starting and ending work before or after the rush hour (Kumar, 2013).

Another key and upcoming areas of work life balance is what is called, Telecommuting. According to Kalliath and Brough (2008), this also called, 'telework' or 'telecommuting.' This form or work life balance is said to be advantageous for workers by allowing them: to organize their work day around their personal and family needs; to decrease work-related expenses; to reduce commuting time; and to work in a less stressful and disruptive environment (Grant, 2007). In addition, a compressed work week is an arrangement whereby employees work longer shifts in exchange for a reduction in the number of working days in their work cycle. This can be beneficial for employees in terms of additional days off work and reduced commuting time, whereas employers can extend their daily operating hours, with less need to resort to overtime (Hill and Hawkins, 2012). There are some employees who may decide to pick up work on part time basis. In some companies, the idea of part time has been embraced as a form of work life balance, as mentioned by Duncan, (2004), Part-time arrangement which allow employees with health problems, disabilities or limited disposable time like students to participate in the labor force, develop their skills and obtain work experience. Also, Job sharing is an arrangement which allows two employees to jointly fill one fulltime job, with responsibilities and working time shared or divided between them. Job sharing may be appropriate where opportunities for part-time jobs or other arrangements are limited (Casper \& Harris, 2008).

\subsection{Importance of Work Life Balance}

It has been noticed that the spillover of negative aspect of work into an employee's personal life can lead to job exhaustion, disruption of relationships with family and friends, loss of enjoyment, and increased stress (Hill and Hawkins, 2012). Work-life balance is therefore important because it helps create and maintain supportive and healthy work environments, which will enable employees to have balance between work and personal responsibilities and consequently strengthen employee loyalty and productivity (Lowe, 2005). Also, it has been observed by Beauregard, (2006) that, individuals who are persistently tied to their jobs deal with the symptoms of stress and burnout. If a person does not have time to relax and recharge, their ability to do their job decreases and their performance level suffers. Therefore, from a management point of view, it is important to encourage a person to take time off from work instead of putting in long hours. Creating a schedule that allows a person to do activities they enjoy will help them to be better employees, friends, and family members. Once the time to work is over the person needs to learn to walk away from their work and not answer work calls. This type of balance is not easy to achieve because there will always be people who want to make demands on an individual's time. People need to learn that it is okay to say no and only agree to take on additional tasks if they are important (Duncan, 2004). In an endeavor to explain about the significance of work life balance, Lazar (2010) suggests those employees who have some form of control over their working environment tend to suffer less stress-related ill-health, with clear implications for the concept of work-life balance. That is, without creating a work-life balance a person isn't able to take time to enjoy the life they have worked so hard to create. They aren't available for friends and family members, and often take their stress out on the ones they love. They can also suffer from illness and physical disorders that stem from prolonged stress such as heart disease, alcoholism, and even diabetes (Lowe, 2005).

\subsection{Work Life Balance and General Organizational Performance}

This review applies to work life balance as applied generally to the performance of an organization, even those that are not in the banking sector. The term performance, in this context, implies the accumulated end result of all the organization's work process and activities (Casper \& Harris, 2008). Employee Performance Management is a process for establishing a shared workforce understanding about what is to be achieved at an organization level. It is about aligning the organizational objectives with the employees' agreed measures, skills, competency requirements, development plans and the delivery of results. It was found in a study by Casper \& Harris, (2008) that, competing demands between work and home have assumed increased relevance for employees in recent years. As a result of the demographic and workplace changes such as rising numbers of women in the labor force, an ageing population, longer working hours, and more sophisticated communications technology enabling near constant contact with the workplace.

In response to these changes and the conflict they generate among the multiple roles that individuals occupy, organizations are increasingly pressured to implement work practices intended to facilitate employees' efforts to fulfil both their employment related and their personal responsibilities (Rapoport, Bailyn, Fletcher, \& Pruitt, 2002). All of these factors, in turn, affect job performance, direct and indirect absenteeism costs, costs associated with the loss and replacement of valued employees, customer satisfaction, 
and organizational productivity; although the formal evaluation of work-life practices is often difficult because of the problem of calculating the costs and benefits of different strategies, some companies have attempted to quantify the outcomes of specific policies (Beauregard, 2006).

Productivity is critical for the long-term competitiveness and profitability of organisations. Studies have showed that the experience of work-life balance is positively related to employees' performance and organizational performance as well (Casper, W. J., \& Harris 2008). More specifically, work-life balance has been shown to have positive outcomes, such as low turnover intention, improvement of performance, and job satisfaction. Work-life balance has a positive effect on employee's affective commitment to their organisations (Casper et al., 2011). That is, the experience of work-life balance generates feelings of loyalty to the organization and increases affective commitment. Affective commitment is an emotional attachment to the organisations or the employers which can cause employees to want to remain with the organisations.

The experience of psychological well-being and harmony in life helps employees concentrate on their work, resulting in better performance. Studies have found that work-life conflict is associated with stress, depression, and a variety of stress-related poor health and mental health effects, and that such ill health increases work absenteeism, turnover, and low morale (Emslie et al., 2004). In their narrative review, (Beauregard and Henry, 2009) observed evidence for a positive effect of organizational work-life balance practices on recruitment, retention, attendance (including turnover intention), and productivity. One explanation is that employees reciprocate with increased loyalty, effort and productivity in exchange for the organization's practical assistance with managing work-life demands, and in appreciation for the organization's indication of care and concern as demonstrated by work-life policies and practices (Beauregard and Henry, 2009). There is a wealth of information that outlines the advantages of offering flexible and special leave arrangements to employees in terms of improving staff recruitment, reducing turn-over, absenteeism and the costs associated with all this as well as increasing employee satisfaction and performance.

\subsection{Work Life Balance as applied to the Banking Sector}

This review applies to work life balance as applied specifically to the banking sector. The Banking industry is a fast growing industry especially with the entry of private sector and foreign banks have brought various essential changes in the banking industry. The threat of work- life imbalance is highly noticeable in banking industry (Beauregard, 2006). As reported by Garg \& Rastogi (2006), employees in the banks take painful effort to deliver the various needs of its customers. Work deadlines are getting compact and the individual's jobs are loaded and added with quality output. As a result of work pressure, it becomes hard to maintain balance between professional and family life. The output of the banking sector is dependent on the quality of human resources. The basic function of human resource development is to facilitate performance improvement, measured in terms of finance indicators of operational efficiency and quality of financial services provided. The twin challenges faced by the banks' managements are that of retaining the prevailing employees and providing a satisfying work environment for all employees (Ametorwo, 2016).

Insufficient work life balance is a challenge that poses a big risk to banking workers' wellbeing, their performance as well as the organisational performance (Wambui, 2017). Numerous bank employees often have problems in endeavoring to balance employment responsibilities with their social life. Given the benefits of work-life balance practices and the potential to help improve employee job performance in terms of increased organisational commitment, job satisfaction, reduction on the turnover rate, ECO Bank has for instance, introduced programs to assist the employees in achieving a balanced work life which include; flexible working hours, employee assistance programs and leave programs. However there is no study which has been carried out to determine the success of the work-life balance programs at the bank. It is against this background that the study sought to determine the effects of organizational work-life balance programs on employee job performance at ECO Bank Kenya. (Kamau, J. M., Muleke, V., Mukaya, S.O. \& Wagoki, J. 2013).

Bank is a customer oriented services industry. Efficacy of customer service is related with progressive operation. In the competitive banking industry, customer satisfaction is considered as the essence of success. Organizations operating in service industries should consider service quality a key strategic issue for the business success (Spathis, 2004). Those service providers who establish a high level of service quality retain a high level of customer satisfaction; they also obtained a sustainable competitive advantage. Research indicates that companies with an excellent customer service record reported a $72 \%$ increase in profit per employee, compared to similar organizations that have demonstrated poor customer service; it is also five times costlier to attract new customers than to retain existing customers (Duncan, 2004). The outcome of good work-life balance is very viable by creating a good customer service, culture of honesty and trust where staff can admit to home problems and get support (Maxwell and McDougall, 2004). Hall and Ritcher (1998) argued that the employee needs to have clear boundaries between the two domains and some degree of separation, too much overlap between work and home can cause employee burnout and dissatisfaction. This may suggest that when people are happier with their work role and family life, they will be more likely to help others and be more enjoyable to work with.

\subsection{METHODOLOGY}

The study used a mixed method design employing both qualitative and quantitative methods. The target population for the study were all the employees of AB Bank Zambia in Lusaka which comes to a total of 500. The sample for the study was 222 members of staff who were selected from various departments of the bank so as to get different views from diverse sections and departments of the bank. Purposive sampling was used to select the 22 managers to be interviewed, and the stratified and simple random sampling were used to select equal numbers of people from the various departments and branches to make up the 200 members of staff. 
ISSN 2250-3153

Collection of data included instruments such us questionnaires and informal unstructured interviews. Phone call Interviews were used with management staff to get more information on the implementation of work life balance at AB Bank Zambia. Ethical approval was granted by top management of AB Bank Zambia. Data was analysed using SPSS for quantitative data gathered through questionnaires and content analysis for qualitative data.

\subsection{DISCUSSIONS OF RESEARCH FINDINGS}

\subsection{The Implementation/ Practice of Work Life Balance at AB Bank Zambia}

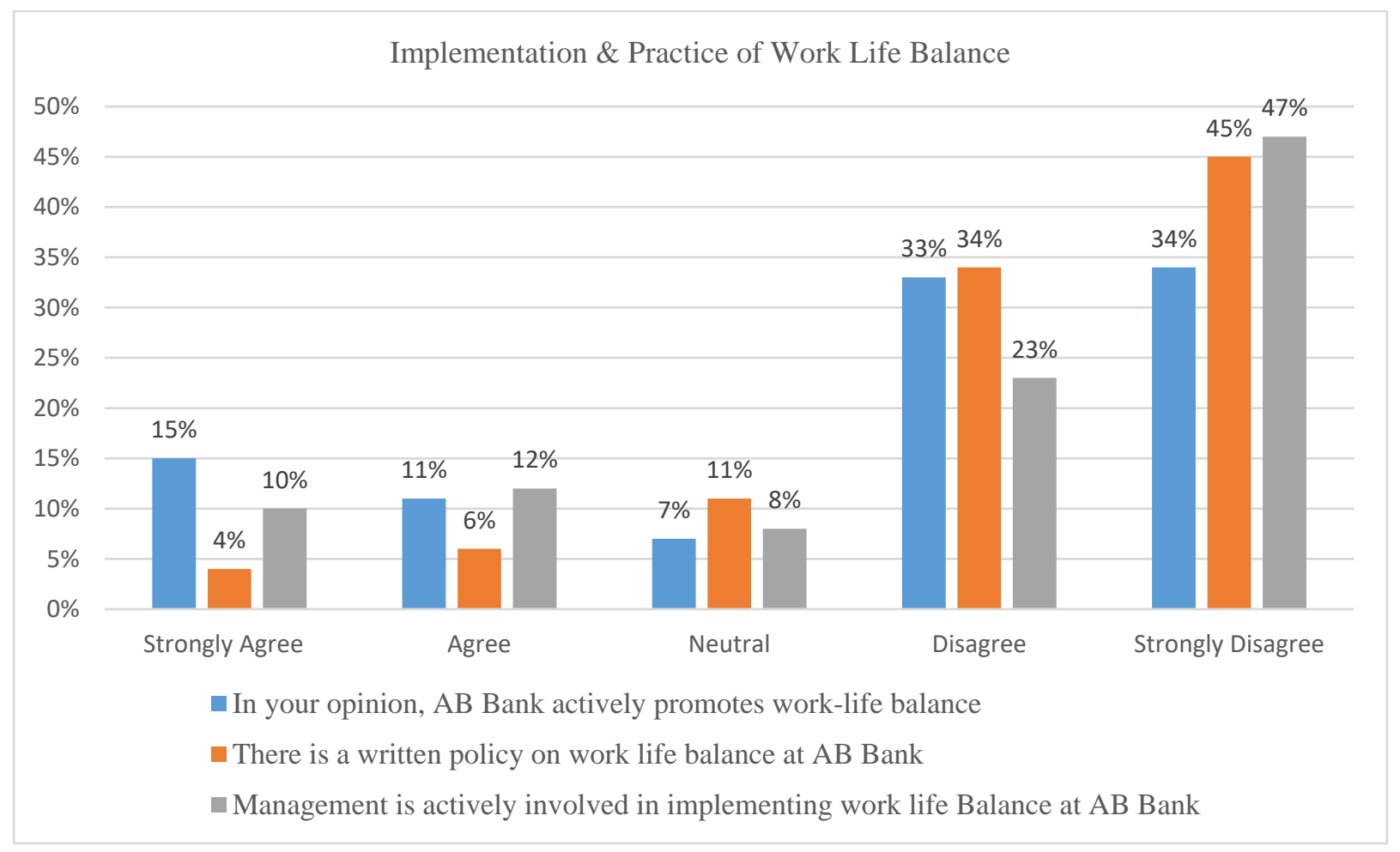

Source: Field data (2020)

From the figure shown above, the implementation and practice of work life balance at AB Bank Zambia shows that $34 \%$, $45 \%$ and $47 \%$ stated that they 'strongly disagree', pointing to the fact that employees had no written policy on work life balance. Also, it showed that management was not even actively involved in the implementation of work life balance. A Branch Head of AB Bank for instance indicated that the work-life balance program at $\mathrm{AB}$ Bank needs refinement. An Operations Manager also shared the same view; he believes that work-life programs at AB Bank needs a refinement. There were others who believed that the status of work-life balance system in place at AB Bank was satisfactory, no respondent praised the work-life system in place at AB Bank. A senior manager of the bank, for instance replied that he finds work-life balance systems in place at AB Bank to be satisfactory when he was asked to comment about the status of work-life balance at AB Bank. Another manager remarked that "I believe that there is a lot of room for improvement as far as work-life balance initiatives and execution is concerned, employees should be actively involved in developing such initiatives", this sums up the overall impression of staff members of AB Bank.

\subsection{Effect of Work Life Balance on Employee Performance at AB Bank}




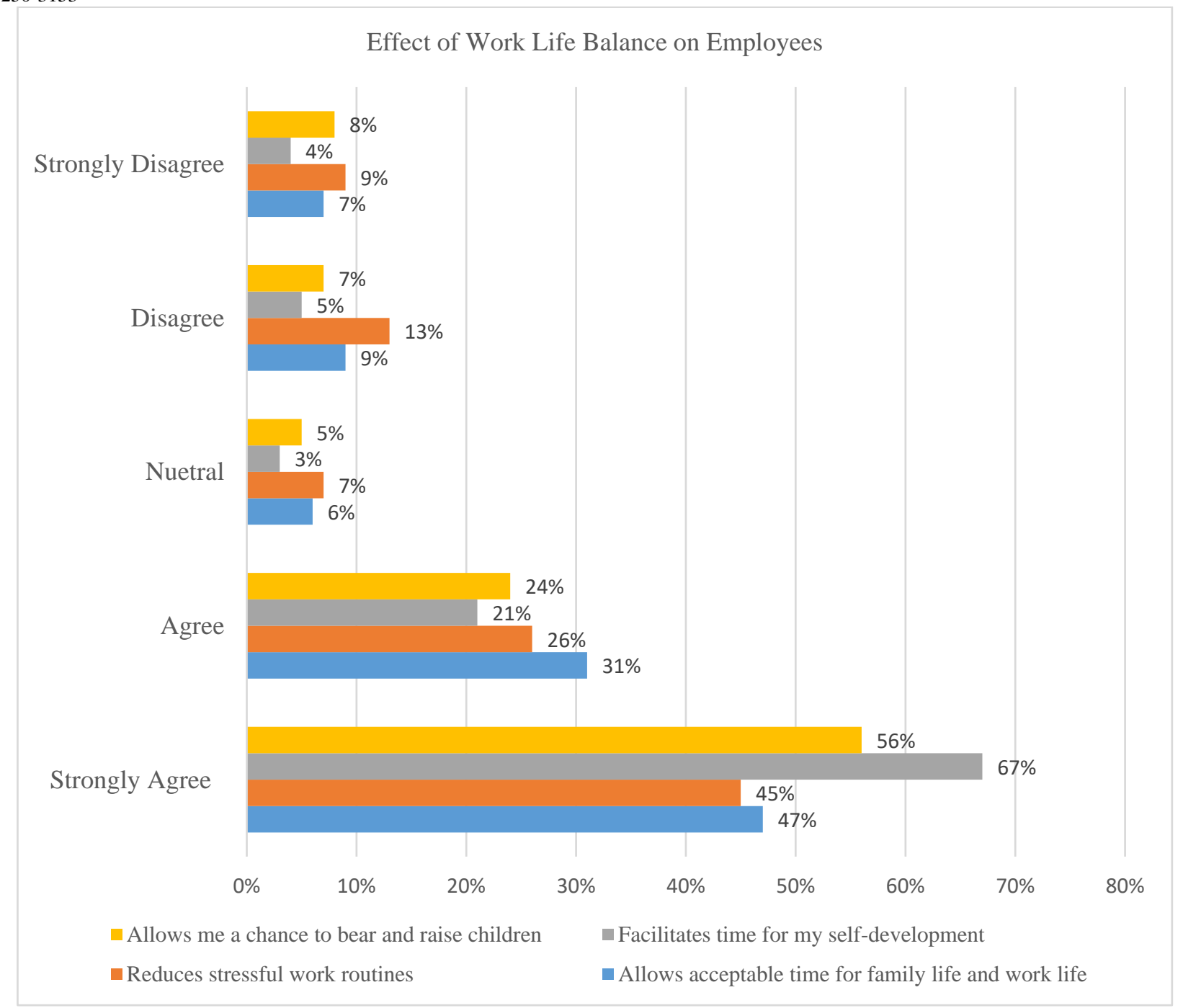

Source: Field data (2020)

In order to find out generally what the effects of work life balance would be, with five options given, the majority of the employees, $56 \%, 67 \%, 45 \%$, and $47 \%$ all strongly agreed that work life balance would allow them a chance to bear and raise children, find time for personal development, reduces stress and create time for family. In as much as work life balance may not be a priority at AB Bank, respondents agreed that its availability would be of great personal benefit to them. It can be implied then that work life balance should be good for employees' performance and consequently organisational performance.

\subsection{Job Interference with Personal Lives}

A study on the above subject found that most bank staff find their jobs interfering with their personal priorities more than their personal priorities interfering with their job. On the level of stress experienced in the last six months, $78.3 \%$ indicated that they had experienced significant stress as a result of their job. This suggests an increasing stress on most staff of AB bank which the researcher attributed to recent job demands. About $73.1 \%$ of respondents reported good control on their job. Findings in connection with respondents' ability to exercise control over managing their time revealed that most staff (representing 68.5\%) are time conscious and are able to exercise control over their time. This was attributed to the nature of service rendered by banks which required one to be efficient with time. In interviews, managers were asked if and how the bank manages stress, and most respondents did not report job sharing as an active practice at the bank. It was concluded that job sharing was not a policy, regardless of its recognition as one mechanism that contributes to work-life balance. One manager also reported non-flexibility in working arrangements which suggested that there was no mechanism to ensure flexibility in work conditions at the bank. There was an unanimous response that only the annual leave provisions create some conditions for staff to balance work and life. There was no provision found limited to staff without children.

\subsection{Obstacles of Work Life balance at AB Bank}

$69 \%$ of respondents pointed to the tight nature of work schedules as one challenge to effective work-life balance. Again, most respondents confirmed that the only visible work-life balance option was available to new mothers through maternity leave and compassionate leave when the child is sick. Respondents also identified the fact that usually, requests to change working patterns 
are not received positively by the employer. This implies that if it is not a recommendation from the top, most staff are likely not to have their request for a job change approved.

It was also found that the flexible working options available to staff were usually restrictive. Comments also revealed that flexible working options were usually available to non-core staff that had very little opportunity for progression and also some members in authority. Respondents also revealed that usually employees who seek to further their training or education have to contend with several challenges. A number of respondents to the interviews also agreed that the flexible working hours available are restrictive, thus flexibility was within a narrow range of choices, and this could be seen as half-hearted desire to grant flexible working options. It was also reported that the work-life balance programs at AB Bank is that most employees feel that working arrangements are so tight, they cannot be said to be flexible. Many interviewees reported that tight work schedules were one of their main challenges at AB Bank. This points in-part to the fact that the work schedules are very tasking; this phenomenon is common among most Zambian Banks.

4.6 Work Life Balance and Performance of employees at AB Bank

Correlation between Work Life Balance Practice and Employee Performance

\begin{tabular}{|l|l|}
\hline Pearson Correlation & 0.70825 \\
\hline Sig. (1 Tailed) & 0.000 \\
\hline
\end{tabular}

Pearson correlation between the two variables is 0.70825 , which is positive. It shows that there is a positive association between work life balance practices and employee performance of both categories. This relationship is statistically significant as correlation significant at 0.01 level (1- tailed). Therefore, there is statistical evidence to claim that work life balance practices and employee performance are positively related. Here relationship was statistically significant at $99 \%$ confidence level $(\mathrm{p}<.01)$.

Correlation between Dimensions of Work Life Balance Practices and Employee Performance

\begin{tabular}{|l|l|l|l|l|}
\hline & LA & PPP & FWS & FSWP \\
\hline Leave Arrangement (LA) & \multicolumn{1}{|c|}{1} & & & \\
\hline $\begin{array}{l}\text { Parenting and Pregnancy Policies } \\
\text { (PPP) }\end{array}$ & .750 & 1 & & \\
\hline $\begin{array}{l}\text { Flexible Work Arrangements } \\
\text { (FSW) }\end{array}$ & $\mathbf{. 6 4 0}$ & $\mathbf{. 7 0 7}$ & $\mathbf{6 9 3}$ & $\mathbf{1}$ \\
\hline $\begin{array}{l}\text { Family supportive work } \\
\text { provision (FSWP) }\end{array}$ & $\mathbf{. 7 4 7}$ & $\mathbf{. 6 9 9}$ & $\mathbf{. 6 8 7}$ & $\mathbf{. 7 5 6}$ \\
\hline Employee performance (EP) & $\mathbf{. 7 1 4}$ & $\mathbf{. 6 7 6}$ & & \\
\hline
\end{tabular}

As shown from the table above, leave arrangement $(\mathrm{r}=.714, \mathrm{p}<0.01)$ was positively related to employee performance. According to the theory $r$ value $=0.50$, it indicates moderate uphill (positive) relationship and $r=0.70$ represent a strong uphill (positive) linear relationship. Therefore, there is a strong positive relationship between leave arrangement and employee performance and statistically significant at $99 \%$ confidence level $(\mathrm{p}<0.01)$. Further, parent and pregnancy policy $(\mathrm{r}=0.676, \mathrm{p}<0.01)$ was positively related to employee performance. At this point there was no strong positive relationship but (0.676) value indicated an approximately strong positive relationship between parent and pregnancy policy and employee performance. Also relationship was statistically significant at $99 \%$ confidence level $(\mathrm{p}<0.01)$. The findings also revealed that there is a positive relationship between flexible work arrangement $(r=0.687, \mathrm{p}<0.01)$ and employee performance. Although there was no strong correlation, coefficient indicated approximately a strong positive relationship between flexible work arrangement and employee performance while relationship statistically significant at $99 \%$ confidence level.

According to the results of simple regression analysis, work life balance was found to have a positive impact on employee performance with the strength of $b$ value of 0.382 . Hence, work life balance practices were found to be a predictor of employee performance.

Result of Regression Analysis

\begin{tabular}{|c|c|}
\hline $\mathbf{R}$ & $\mathbf{0 . 7 5 6}$ \\
\hline $\mathbf{R}^{2}$ & $\mathbf{0 . 5 7 1}$ \\
\hline Adjusted R & $\mathbf{0 . 5 6 8}$ \\
\hline$\Delta \mathbf{F}$ & $\mathbf{1 7 8 . 6 7 3}$ \\
\hline Sig. $\Delta \mathbf{F}$ & $\mathbf{0 . 0 0 0}$ \\
\hline B (beta) & $\mathbf{0 . 3 9 5}$ \\
\hline SD & $\mathbf{0 . 9 5 6 1 3}$ \\
\hline
\end{tabular}

As presented in Table above, $\mathrm{R}$ value is 0.7082 and it represents strong correlation between the predictors and outcome which in this study are work life balance practices and employee performance. The $\mathrm{b}$ value of the equation, the gradient of the regression, is 0.395 , which is significant at $1 \%$ (significant $=0.000$ ). As indicated by $\mathrm{R}$ squared, $56.8 \%$ of the variance of the employee performance is explained by work life balance practices with the standardized beta of 0.571 . The $\mathrm{F}$ value is 178.673 , which is 
significant at $1 \%(\mathrm{p}=0.000)$, which suggests that work life balance has significantly explained $56.8 \%$ of the variance of employee performance.

Result of Regression Analysis for each Dimension of Work Life Balance Practices

\begin{tabular}{|l|l|l|l|l|}
\hline Variables & SD & B (beta) & t & Sig \\
\hline Independent variable & & & & \\
\hline Family supportive work provision & .926 & .382 & 4.48 & .00 \\
\hline Flexible work arrangement & $\mathbf{1 . 0 7 2}$ &. $\mathbf{2 5 0}$ & $\mathbf{3 . 3 9}$ & $\mathbf{. 0 0 1}$ \\
\hline Leave arrangement & .881 & .268 & $\mathbf{3 . 3 6}$ & .001 \\
\hline Constant & & $\mathbf{4 0 . 1 9 8}$ & & \\
\hline
\end{tabular}

The study aslo used stepwise method in regression analysis because this study focuses four dimensions as one independent variable. Parenting and pregnancy policy is excluded from the model due to non-significance ( $\mathrm{p}>.01$ ). As shown in Table above, $\mathrm{R}$ value is 0.808 and it represents strong correlation between the predictors and outcome which in this study are work life balance practices and employee performance. The next column gives value of R square, which measures how much of the variability in the dependent variable is accounted by the independent variable. In this study, it measured how much of the variability of employee performance happens due to family supportive work provision, flexible work arrangement and leave arrangement. Table 7, model one showed; its value is .571 , which means that family supportive work provision for $57.1 \%$ of the variation in employee performance. However, other two included the value increased to $65.2 \%$ of the variance in employee performance. So, when family supportive work provision for $57.1 \%$ and flexible work arrangement for $5.1 \%$ and additional $3 \%$ imply leave arrangement in employee performance.

From the findings above the study considered the relationships among leave arrangement, parenting and pregnancy policy, flexible work arrangement, and family supportive work provision and employee performance. This study used correlation analysis and it indicates strong positive relationships among family supportive work provision, leave arrangement and employee performance. Also there are approximately strong positive relationships among parenting and pregnancy policy, flexible work arrangement and employee performance of the organisations. In as much as this research shows that the practice of work life balance at AB Bank is not effective, it has been proven by the findings in this study that the organization can enhance their employee's performance by increasing flexible work arrangement within the organization. To see the impact leave arrangement would have on employee performance, the researcher used regression analysis. According to this study it indicates that there is a positive impact of leave arrangement on employee performance and when leave arrangement is increased by 0.881 , employee performance is increased by 2.6. Therefore the organisations can increase different leave options by identifying their employees' needs. Findings of this study reveal that parenting and pregnancy policy has no impact to the employee's performance. Pregnant and parent employees mainly expect maternity leave for adoption and it is covered from the leave arrangements. As a result, reasonably pregnancy and parent policy do not impact on performance of the organisations. The impact of flexible work arrangements on employee performance and findings of this study reveal that flexible work arrangements positively impact on employee performance. There is no any flexible working schedule in the bank because of tight working hours. Here flexible work arrangement represents job sharing and compressed work week and those are felt significantly by the employees to balance their work life. The result of this study indicates flexible work arrangements would positively impact on employees' performance in this context. Finally the impact of family supportive work provisions on employee performance and findings of this study show that family supportive work provision positively impacts on employee performance. When comparing with the other dimensions of work life balance practices, there is a high impact of this dimension because employees sense new experience by participating in different programs. Therefore, the organizations always regard employees' changing needs and create supportive programs based on them.

The present findings also highlight the need to develop more supportive family programs, different leave options which facilitate employees' needs and flexible working arrangements within the organisations. This finding supports much of the literature, which examined the impact of work life balance practices of the organization with employee performance. When the organization has better work life balance practices, significantly affect enhancing employee performance (Peggy, 2007). There is a positive relationship between work life balance practices and employee performance and findings reveal employee performance increases by 0.382 when work life balance practices are increased by 0.95613 . Hence, results of this research support the pervious researchers' findings. According to the above findings, performance of employees can be enhanced by increasing different work life balance practices options.

It is evident that the issues regarding work-balance is persistent because of various factors such as work environment, Human Resource policies, job insecurities, compensation packages and so on. It was found that employees experienced significant stress as a result of their job. This suggests an increasing stress on most staff of AB Bank which the study attributed to recent job demands. However, a number of respondents also reported good control on their job. Findings in connection with respondents' ability to exercise control over managing their time revealed that most staff are time conscious and are able to exercise control over their time. It was discovered that, although the bank has some systems for managing stress, they did not have explicit policies and practices for implementing work life balance. The implementation of work life balance was left to the managers who decided who it would be carried out to. However, the bank had some usual human resources policies like leave, including maternity leave, which helped parents take care of their new born babies. 
While employers are in essence not answerable for giving work life balance to their employees, they can support employees to seek and maintain their own work balance. Where the right balance is established and maintained, both the employee and the employer gains. For the employee there is enhance happiness, superior dealings with management, successful communication, better sense of worth, health, attentiveness and self-assurance, enhanced management of tasks and lower levels of stress. In the same vein, the organization is able to take full advantage of existing human resourses, has superior appeal to a wider variety of applicants, has added workforce devotion and drive, lower non-attendance and greater output. Respondents pointed to the tight nature of work schedules as one challenge to effective work-life balance. Respondents also identified the fact that usually, requests to change working patterns are not received positively by the employer. This implies that if it is not a recommendation from the top, most members of staff are likely not to have their request for a job change approved. It was also found that the flexible working options available to staff were usually restrictive.

However, the study revealed that a system of work life balance, in the banking industry, would be a good initiative in improving employee performance. This research concludes that work life balance has great association with employee performance.

\section{CONCLUSION AND RECOMMENDATIONS}

In the light of the present research, it is evident that the issue of work-life balance is persistent because of various obstacles such as work environment, human resource policies, job insecurities, compensation packages etc. It is concluded that in terms of work balance, employees experienced significant stress as a result of their job which affects their performance at work. This suggested that there is an increasing work-life imbalance and stress of most of the members of staff at AB Bank which the research attributed to job demands.

It is against this background that the following recommendations were made to the management of AB Bank. Firstly, appropriate policies and initiatives must be implemented by the bank's human resource department to ensure that there are no obstacles in the practice of work life balance i.e written policy on work life balance. Secondly, stress management and conducting training programmes in relation to work life balance through which the organization can improve the Work Life Balance of their staff. e.g. time management and personal effectiveness, effective work load management should be prioritized in order to improve performance among employees.

\section{REFERENCES}

Ametorwo, A. (2016) "Managing Work Family Conflict among Female Entrepreneurs in Ghana for Development. International Journal of Economics," Business and Management Studies, Vol. 3, No.1, pp.21-35

Beauregard, T. A. (2006) "Predicting Interference between Work and Home: A Comparison of Dispositional and Situational Antecedents, ” Journal of Managerial Psychology, Vol.21, No.3, pp.244-264

Blumberg, B., Cooper, D. C., \& Schindler, P. S. (2011) Business Research Methods, London, UK: McGraw-Hill.

Bodibe, O. (2006) The Extent and Effects of Casualisation in Southern Africa, Eastern Cape: Free Press

Casper, W. J., \& Harris, C. M. (2008) "Work-Life Benefits and Organisational Attachment: Self-Interest Utility And Signaling Theory Models." Journal of Vocational Behaviour, Vol.72, pp.95-109

Davies, M.L. (2008) “Gender, Education, Extremism and Security, Compare," A journal of comparative education, Vol.38, No.5, pp. 611-625

Garg, P. \& Rastogi, R., (2006) "New Model of Job Design: Motivating Employees' Performances," Journal of Management Development, Vol.25, No.6, pp. 572-587

Grant, A. M. (2007) "Relational Job Design and Motivation,” Academy of Management Review, Vol.32, No.2, pp.393-417

Hall, D. \& Richter, J. (1988) "Balancing Work Life And Home Life: What Can Organisations Do To Help?" The Academy of Management Executive, Vol.2, No.3, pp.213-223

Hill E.J., and Hawkins A.J. (2012) "Finding an Extra Day a Week: The Positive Influence of Perceived Job Flexibility on Work and Family Life Balance." Family Relations, Vol, No. 11, 50:49

Kalliath, T. and Brough, P. (2008) Work-Life Balance: A Review of the Meaning of the Balance Construct. Journal of Management Organisation Vol.14, pp.323-327

Kamau, J. M., Muleke, V., Mukaya, S.O. \& Wagoki, J. (2013) "Work-Life Balance Practices on Employee Job Performance at Eco Bank Kenya." European Journal of Business and Management, Vol.5, No.25, pp. 11-26

Labaree, R.V. (2009) Theory Building: Using Abductive Search Strategies, Singapore: Springer Nature

Lazăr, I., (2010) “The Role of Work-Life Balance Practices in Order to Improve Organisational Performance," European Research Studies, Vol. 13, No.1, pp. 57-77

Lowe, K. (2005) The Importance of Work-Life-Balance, London: Macmillan Books

Maxwell, G. \& McDougall, M. (2004) “Work-life balance,” Public Management Review, Vol.6, No.3, pp.377-393

Spathis, C., Petridou, E. and Glaveli, N. (2004) Managing Service Quality in Banks: Customers Gender Effects, London: Emerald Group Publishing Limited

Tausig, M., and Fenwick, R., (2011) “Unbinding Time: Alternate Work Schedules and Work-Life Balance,” Journal of Family and Economic Issues, Vol.22, No.2, pp.101-119

Tomlinson, R. (2016) Creating Balance Through Work-life Integration, New Jersey: Sage

This publication is licensed under Creative Commons Attribution CC BY. 
ISSN 2250-3153 